\title{
Chronic rhinosinusitis and emerging treatment options
}

This article was published in the following Dove Press journal:

International Journal of General Medicine

6 June 2013

Number of times this article has been viewed

\section{Patorn Piromchai ${ }^{1,2}$ \\ Pornthep Kasemsiri, ${ }^{1,3}$ \\ Supawan Laohasiriwong' \\ Sanguansak \\ Thanaviratananich' \\ 'Department of Otorhinolaryngology, Faculty of Medicine, Khon Kaen University, Khon Kaen, Thailand; \\ ${ }^{2}$ Department of Otolaryngology, Royal Victorian Eye and Ear Hospital/ University of Melbourne, East Melbourne, Australia; ${ }^{3}$ Department of Otolaryngology - Head and Neck Surgery, Wexner Medical Center at the Ohio State University Medical Center, Columbus, Ohio, USA}

\begin{abstract}
This review describes the epidemiology and various treatments in chronic rhinosinusitis (CRS) with nasal polyps (CRSwNP) and CRS without nasal polyps (CRSsNP). Evidence for short-term use of systemic corticosteroids has been shown to be favorable in CRSwNP, but still limited in CRSsNP. Topical corticosteroids improve symptom scores in both CRS subgroups. The role of microbes in CRS is still controversial. Culture-directed antibiotics are recommended for CRSsNP with exacerbation. Long-term use of low dosage antibiotics is recommended for CRSsNP for their anti-inflammatory effects. Other emerging treatment options are also discussed.
\end{abstract}

Keywords: rhinosinusitis, chronic, nasal polyps, therapy, sinus

\section{Clinical characteristics of chronic rhinosinusitis}

Rhinosinusitis is an inflammatory disease of the nasal and paranasal sinus mucosa. It is defined as chronic when it lasts longer than 3 months without complete symptom resolution. Diagnostic criteria consist of the presence of symptoms including purulent nasal discharge, nasal obstruction, facial pain/pressure/fullness, and/or decreased sense of smell plus either endoscopic findings of inflammation, purulent discharge or edema of the middle meatus or ethmoid region, polyps in the nasal cavity or the middle meatus, and/or radiographic imaging showing inflammation of the paranasal sinuses. ${ }^{1,2}$ Chronic rhinosinusitis (CRS) is further divided into CRS with nasal polyps (CRSwNP) and CRS without nasal polyps (CRSsNP). As for the use in epidemiologic studies, CRS is defined as the presence of two or more symptoms, one of which should be either nasal blockage/obstruction/congestion or nasal discharge (anterior/posterior nasal drip) and/or facial pain/pressure and/or reduction or loss of smell for more than 12 weeks with validation by telephone or interview. ${ }^{1,3}$

The pathogenesis of CRS remains controversial. Multifactorial factors altering the host-environment interaction such as bacteria, fungi, viruses, allergens, or environmental toxins may trigger the inflammatory process.

\section{Epidemiology of chronic rhinosinusitis and associated complications}

CRS is a common health problem which significantly affects quality of life. CRS has a significant impact on patients in seven of eight domains of the 36-item short form health survey (SF-36). ${ }^{4}$ Patients have significantly higher bodily pain and decreased social function compared to other chronic diseases (congestive heart failure, angina, 
chronic obstructive pulmonary disease, and back pain) $(P<0.05) .^{5}$ According to a US national health interview survey of the prevalence of chronic conditions, CRS has been estimated to affect $12.5 \%$ to $15.5 \%$ of the total population, making it the second most common chronic condition in the United States. ${ }^{6,7}$ However, the prevalence of doctordiagnosed CRS is much lower; a prevalence of $2 \%$ was found using International Statistical Classification of Diseases and Related Health Problems (ICD)-10 codes as an identifier. ${ }^{8}$ The prevalence rate is substantially higher in females with a female:male ratio of $6: 4^{7}$ and increases with age, with a mean of $2.7 \%$ and $6.6 \%$ in the age groups of 20 to 29 years and 50 to 59 years, respectively, and leveling off at $4.7 \%$ after 60 years. ${ }^{9}$

An epidemiology study in Europe was conducted by The Global Allergy and Asthma Network of Excellence (GA2LEN) by sending questionnaires on The European Position Paper on Rhinosinusitis and Nasal Polyps (EPOS) criteria to a random sample of adults aged 15-75 years. ${ }^{10}$ They found the overall prevalence of CRS was $10.9 \%$, which confirmed the burden as a common chronic disease and pointed out the underestimation of this disease.

\section{Pathogenesis}

The etiology and pathogenesis of chronic rhinosinusitis are not clearly understood. Traditionally, it was believed that the chronic inflammatory process is the end stage of untreated or partially treated acute rhinosinusitis or severe atopy from nasal polyps. This hypothesis leads to the use of antibiotics and anti-inflammatory drugs, eg, corticosteroids for treating CRS patients. Alternative hypotheses include excessive host response to fungi, ${ }^{11,12}$ aspirin intolerance due to defects in the eicosanoid pathway, ${ }^{13,14}$ staphylococcal superantigen resulting in exotoxin effects including tissue damage, ${ }^{15,16}$ coordinated mechanical barrier and the innate immune response of the sinonasal mucosa, ${ }^{17}$ defects in the immune barrier and biofilms formation. ${ }^{18}$

There is a growing body of evidence supporting an emerging hypothesis that a dysfunctional host-environment interaction involving various exogenous agents results in the sinonasal inflammation. In concert with the definition of CRS as an inflammatory disorder, there has been movement away from pathogen-driven hypotheses. This overall concept is in agreement with the current understanding of the etiology and pathogenesis of chronic mucosal inflammatory disorders in general, which describes a balance of interactions between the host, commensal flora, potential pathogens, and exogenous stresses.

\section{Diagnosis}

CRS, with or without nasal polyps in adults is defined as:

- inflammation of the nose and the paranasal sinuses characterized by two or more symptoms, one of which should be either nasal blockage/obstruction/congestion or nasal discharge (anterior/posterior nasal drip) \pm facial pain/ pressure \pm reduction or loss of smell for $\geq 12$ weeks.

This should be supported by demonstrable disease with endoscopic signs of:

- nasal polyps, and/or mucopurulent discharge primarily from middle meatus and/or edema/mucosal obstruction primarily in middle meatus.

and/or

- computed tomography (CT) changes: mucosal changes within the ostiomeatal complex and/or sinuses.

\section{Current and emerging treatment options}

The aims of treatment in CRS include elimination of the infection, reduced sinonasal inflammation, and maintained patent sinonasal passage drainage. In addition, CRS may be associated with precipitating factors including allergies, cystic fibrosis, gastroesophageal reflux, sinonasal anatomic obstruction in the ostiomeatal unit, and immunologic disorders. Therefore, the management of these risk factors should also be optimized.

Treatment of CRS includes medical and surgical therapy. Medical therapy often requires combining multiple medications including antibiotics, nasal decongestants, topical nasal steroids and/or oral steroids, and saline irrigation. The rationale of this regimen is to control precipitating factors, treat the infection, reduce mucosal edema, and facilitate drainage. However, some patients do not respond with full medical treatment alone; in these cases treatment with endoscopic sinus surgery should be considered as an alternative. Management schemes for CRSsNP and CRSwNP are displayed in Figures 1 and 2, respectively.

\section{Corticosteroid}

The aim of corticosteroid therapy in CRS is to reduce inflammation via directly reducing eosinophil viability and activation. ${ }^{19,20}$ In addition, an indirect effect can be to reduce the secretion of chemotactic cytokines from the nasal mucosa and polyp's epithelial cells. ${ }^{21-24}$

\section{Systemic corticosteroid}

Oral steroids have been introduced as a systemic form to control inflammation. They are administrated as part of a 


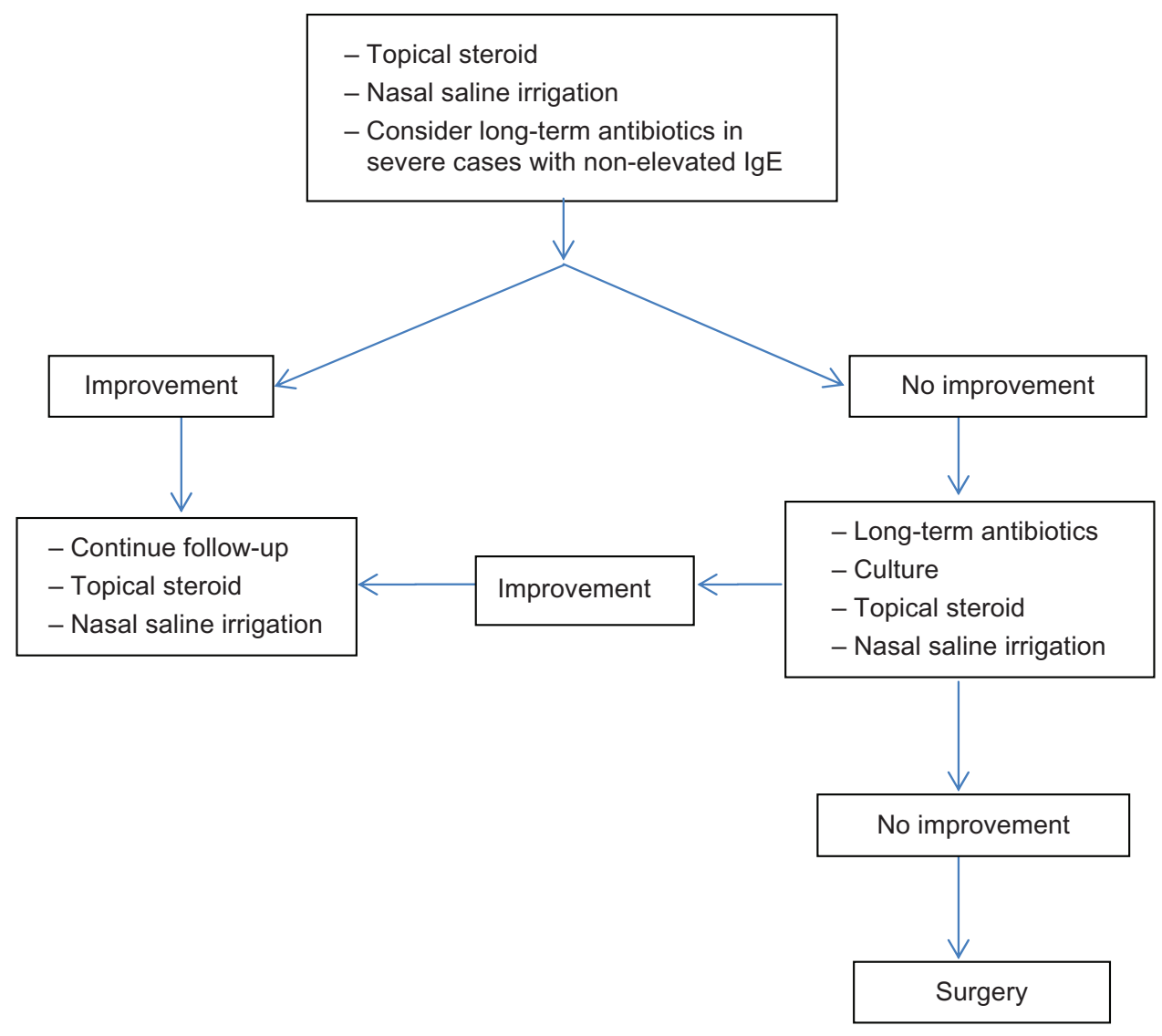

Figure I Management scheme for chronic rhinosinusitis without nasal polyps. Abbreviation: Ig, immunoglobulin.

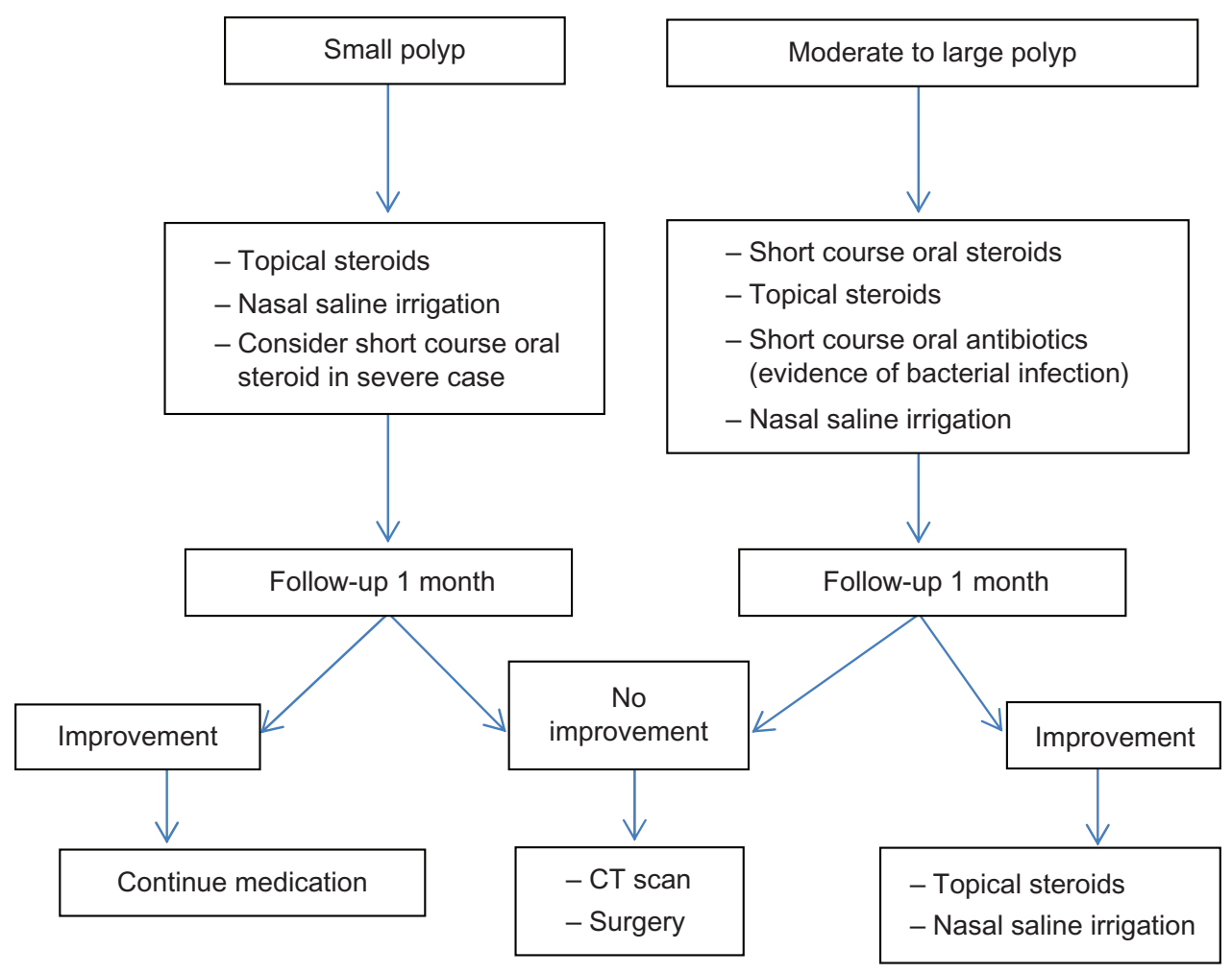

Figure 2 Management scheme for chronic rhinosinusitis with nasal polyps.

Abbreviation: CT, computed tomography. 
multidrug regimen. To date, no evidence advocates for their use alone. ${ }^{25}$

\section{CRSsNP}

There is limited evidence to support the use of oral steroids in CRSsNP. Tosca et $\mathrm{al}^{26}$ investigated the efficacy of oral steroids as part of a multidrug regimen in children with CRS and asthma. They demonstrated better outcomes and cytokine profiles after treatment including improved nasal endoscopic condition in allergic children (87.5\%) and nonallergic children $(85.7 \%)$, statistically significant reduction of inflammatory infiltration in all children $(P<0.05)$, significant decrease of interleukin (IL)-4 in allergic children $(P=0.0002)$ and nonallergic children $(P=0.0007)$, significant increase of interferon-gamma in allergic children $(P=0.03)$, and nonsignificant increase in nonallergic children. Additionally, two retrospective studies investigated the benefit of using oral steroids in a multidrug regimen. Subramanian et $\mathrm{al}^{27}$ reported that $90 \%$ of patients had improved symptoms and/or CT at 6-8 weeks after treatment. Another study by Lal et $\mathrm{al}^{28}$ reported the complete resolution in patients with CRSwNP or CRSsNP at 2 months after treatment (51.03\%). According to this result, a subgroup of CRSsNP was analyzed with a success rate of $54.88 \%$.

Although these results showed beneficial effects of oral steroids, randomized placebo-controlled trials are required to support the use of oral steroids in CRSsNP.

\section{CRSwNP}

According to a recent Cochrane review, ${ }^{29}$ when data of 166 patients were pooled from three randomized controlled trials, the effects favored systemic corticosteroids. Prednisolone $\mathrm{e}^{30-33}$ and methylprednisolone ${ }^{34}$ are most commonly used. Due to the side-effects of corticosteroids, we do not recommend systemic form usage for long-term treatment.

\section{Safety and tolerability}

Adverse systemic effects of treatment with systemic steroids include Cushing's syndrome, steroid induced diabetes, gastric ulcers, gastrointestinal bleeding, and avascular necrosis of the femoral head. ${ }^{35}$ These side-effects are increased with dose and duration of treatment.

\section{Topical corticosteroids}

Topical corticosteroids are used as part of a multidrug regimen. There are numerous preparations that can be classified by systemic bioavailability as first generation intranasal corticosteroids including beclomethasone dipropionate, triamcinolone acetonide, flunisolide, and budesonide; and the newer generation includes fluticasone propionate, mometasone furoate, ciclesonide, and fluticasone furoate. ${ }^{36}$

The delivery method of topical steroids is an imperative factor. Classification of delivery methods can be divided by site (nose or paranasal sinus), volume, and pressure. The delivery methods to the nasal site include drops, sprays, and nebulizers. Paranasal sinus delivery requires devices cannulated through the nose. Volume of delivery method can be divided into low volume, which is defined as a simple spray volume less than $1 \mathrm{~mL}$, or large volume, which is defined as any significant volume more than $60 \mathrm{~mL}$ (eg, simple irrigation syringe, irrigation devices). Delivery method may also be classified as low pressure (eg, spray, nebulizers, instilled solution through a tube, and nonpressure irrigation) and high pressure methods (eg, positive pressure irrigation).

\section{CRSsNP}

Numerous clinical controlled trials have investigated the efficacy of inhaled intranasal corticosteroids. Several studies compared the first generation of inhaled intranasal corticosteroids with placebo. Lund et $\mathrm{al}^{37}$ reported that the use of budesonide $128 \mu \mathrm{g}$ twice a day significantly improved symptom scores $(P<0.05)$. Similarly, Qvarnberg et al ${ }^{38}$ reported the beneficial effects of budesonide $400 \mu \mathrm{g}$ daily. It reduced nasal symptoms to a greater extent than placebo together with a significantly greater reduction in facial pain. In addition, Lavigne et $\mathrm{al}^{39}$ found a decrease in CD-3 $(P=0.02)$ and eosinophils $(P=0.002)$, and a decrease in the density of cells expressing IL-4 $(P=0.0001)$ and IL-5 messenger RNA $(P=0.006)$ after treatment.

Hansen et $\mathrm{al}^{40}$ studied the efficacy of fluticasone $400 \mu \mathrm{g}$ twice a day via an OptiNose device (Optinose US Inc; Yardley, PA, USA). When compared with placebo, it improved mucosal edema $(P=0.015)$, increased peak nasal inspiratory airflow at 4 and 8 weeks $(P=0.006$ and $P=0.03$, respectively), improved magnetic resonance imaging (MRI) scores after 12 weeks $(P=0.039)$, and improved nasal rhinosinusitis outcome measure-31 (RSOM-31) subscale scores at 4 and 8 weeks $(P<0.009$ and $P<0.016$, respectively). In addition, it significantly improved symptoms including sense of smell and nasal discomfort $(P<0.05)$. Conversely, Dijkstra et $\mathrm{al}^{41}$ compared the efficacy of two regimes of fluticasone nasal spray (400 $\mu \mathrm{g}$ versus $800 \mu \mathrm{g}$ twice a day) and placebo. The results showed no significant difference in total symptom score on the 0-100 scale. Similarly, Jorissen et $\mathrm{al}^{42}$ reported no 
significant difference in endoscopic score when mometasone nasal spray was compared with placebo $(P=0.905)$.

Regarding the method of delivery, a meta-analysis showed significantly greater effects in sinus delivery methods (direct cannulation or irrigation post-surgery) than nasal delivery methods (drops, sprays, or nebulizer) $(P=0.04) .{ }^{36}$

Although, the significant benefit of using intranasal corticosteroids is not shown by several studies, ${ }^{41,42}$ the evidence from a meta-analysis ${ }^{36}$ showed benefits in symptom improvement.

\section{CRSwNP}

Thirty-eight randomized controlled trials were included for a meta-analysis. ${ }^{3}$ The steroid agents used were fluticasone propionate, ${ }^{43-56}$ beclomethasone dipropionate, ${ }^{46,51,57-59}$ betamethasone sodium phosphate, ${ }^{60}$ mometasone furoate,${ }^{64}$ flunisolide, ${ }^{65,66}$ and budesonide. ${ }^{67-75}$ When compared to placebo, the steroid group could decrease symptom scores by 0.46 (95\% confidence interval [CI] $0.27-0.65)$ and decrease polyp size score by 0.48 (95\% CI $0.21-0.75)$.

Nasal aerosols and turbuhalers were more effective than nasal sprays in symptom control but there was no difference in polyp size reduction.

\section{Safety and tolerability}

Adverse effects reported were mostly mild or moderate, consisting of local effects at the site of application. Giger et $\mathrm{al}^{76}$ presented side effects including epistaxis, dry nose, nasal burning, nasal itching, sinusitis, pharyngitis, otitis, change of taste, eczema, nausea/diarrheas, nasal irritation, and common cold. Using intranasal corticosteroid is generally safe. It does not provide increased incidence of infection ${ }^{76}$ or candidiasis, ${ }^{37}$ or produce a change in morning serum cortisol level. ${ }^{37}$

\section{Antibiotics}

The role of microbes in CRS as causative agents or for colonization is unclear. Pandak et $\mathrm{al}^{17}$ attempted to prove this controversial issue. The presence of an insignificant number of leukocytes in each sinus and nasopharyngeal swab shown by this study indicated bacterial colonization of sinonasal mucosa, not infection. Although there is substantial evidence of bacterial colonization in CRS, antibiotics still play a major role for occurrences of acute exacerbation of CRS.,78

Bacterial organisms of CRS differ from acute rhinosinusitis. The main organisms include Staphylococcus aureus, Enterobacteriaceae spp., and Pseudomonas spp., and less commonly Streptococcus pneumoniae,
Haemophilus influenza, and beta hemolytic streptococci. In addition, anaerobes (eg, Peptostreptococcus, Prevotella, Porphyromonas, Bacteroides, Fusobacterium species) are possible organisms in CRS.

\section{Systemic antibiotics}

Systemic antibiotic treatment of CRSsNP can be administrated as either short- or long-term treatment. Short-term treatment is defined as the duration of usage less than 4 weeks in order to eradicate the organisms; conversely, long-term treatment is used for anti-inflammatory effects rather than antibacterial effects. Although, infection is not well established to be causative, the expert committee recommended using antibiotics as short-term treatment in CRSsNP with exacerbation with a positive culture. ${ }^{3}$

\section{CRSsNP}

The appropriate antibiotic for short-term treatment is usually broad spectrum to control both aerobic and anaerobic organisms. In addition, beta-lactamase-producing organisms and methicillin-resistant $S$. aureus (MRSA) are possible pathogens, thus empiric antibiotics are frequently prescribed for coverage of these organisms.

Extended spectrum antibiotics (eg, amoxicillin/clavulanic acid, fluoroquinolone) are commonly used. Legent et $\mathrm{al}^{79}$ compared amoxicillin/clavulanic acid with ciprofloxacin. The results showed no significant differences in clinical cure $(51.2 \%$ versus $58.6 \%)$ and bacteriological eradication rate $(90.5 \%$ versus $88.9 \%)$ for amoxicillin/clavulanic acid and ciprofloxacin. This result was similar to the result of Namyslowski et al ${ }^{80}$ which showed no significant difference between amoxicillin/clavulanic acid and cefuroxime axetil in clinical response (95\% versus $88 \%$ ) and bacterial eradication (65\% versus 68\%). Ciprofloxacin and cefuroxime axetil may be a useful alternative choice of therapeutic treatment.

Regarding long-term antibiotic treatment, the antiinflammatory effects of macrolides have been investigated. Numerous studies have demonstrated the efficacy of macrolides in reducing inflammatory markers and an increasing ciliary beat frequency, indicating less sticky secretions. ${ }^{81-85}$ Furthermore, Wallwork et $\mathrm{al}^{86}$ showed a significant anti-inflammatory effect of roxithromycin on the sinonasal outcome test (SNOT)-20 score, nasal endoscopy, saccharin transit time, and IL-8 levels $(P<0.05)$ in a randomized placebo-controlled trial for CRSsNP. Conversely, the result of Videler et al ${ }^{87}$ showed no significant anti-inflammatory effects on SNOT-22, patient response rating scale, visual analog score, and 
SF-36. These different outcomes between the two studies may be explained by using different inclusion criteria. Wallwork et $\mathrm{al}^{86}$ included only patients with CRSsNP, whereas Videler et $\mathrm{al}^{87}$ included both CRSwNP and CRSsNP. Subgroup analysis in the study of Wallwork et $\mathrm{al}^{86}$ demonstrated that the subpopulation of patients with normal immunoglobulin E (IgE) levels had a higher response rate to the macrolide treatment than patients with elevated IgE. Therefore, serum IgE is a helpful indicator to identify responders to long-term macrolide treatment.

The recent Cochrane review ${ }^{78}$ found that there was limited good quality evidence to compare using antibiotics versus placebo in CRS; thus, future well-designed studies should be conducted.

\section{CRSwNP}

There were two randomized placebo controlled trials for short-term antibiotics. ${ }^{34,88}$ Doxycycline $100 \mathrm{mg}$ for 20 days could significantly reduce polyp size and post-nasal drip score ${ }^{34}$ while other antibiotics (quinolone, amoxicillin/ clavulanate, or co-trimoxazole) had no significant effect but had a trend towards benefit. ${ }^{88}$

There was some evidence of long-term antibiotics use for CRSwNP using macrolides which showed a decrease in polyp size and patient symptoms, but all were nonrandomized trials. $^{81,83,89}$

\section{Safety and tolerability}

Common adverse effects of antibiotics include gastrointestinal symptoms, skin rash, and reversible elevation of liver enzymes. Adverse events from antibiotic use in CRS were observed in an amoxicillin/clavulanic acid group (4.4\%) and cefuroxime group (4.3\%). ${ }^{80}$ These events were minor complications; diarrhea was the most common event. However, one serious urticaria occurred in the cefuroxime group. ${ }^{80}$

Resistant bacterial strains from long-term antibiotic treatment are of concern due to using the low dose form which does not reach the minimal inhibitory concentration. A controlled trial found that three of 50 cultures had positive macrolide resistant strains before treatment, and four of 43 cultures had resistant strains after treatment. ${ }^{87}$ Although, there seems to be no significant difference of resistant strains between before and after treatment, increased macrolide-resistant bacterial strains have been reported. ${ }^{90,91}$ Therefore, development of resistant bacterial strains should be monitored by nasal swab culture every 3 months. $^{3}$

\section{Topical antibiotics CRSsNP}

Topical antibiotics have been administrated to treat CRS with the aim of providing higher concentrations of drug and acting directly on the site of infection; however, placebo controlled trials showed only minimal benefit. ${ }^{94,95}$ Desrosiers et al ${ }^{92}$ reported significant improvements in quality of life, symptoms, and sinonasal endoscopic appearance in both the saline and tobramycin group $(P<0.05)$. Similarly, Videler et $\mathrm{al}^{93}$ compared bacitracin/colimycin topical spray with placebo and reported improvements in both groups without significant differences in SF-36 or sinonasal endoscopic appearance. These studies showed no significant additive effects of topical antibiotics; therefore, topical antibiotics should not be used as first-line management but may be prescribed in patients refractory to traditional topical steroids and oral antibiotics. ${ }^{94}$

\section{CRSWNP}

There was no evidence regarding the use of topical antibiotics in CRSwNP.

\section{Safety and tolerability}

The most common adverse effects included intranasal stinging or burning sensation, moderate pain, throat irritation, cough, and dry skin. ${ }^{3}$ However, Desrosiers et al $^{92}$ reported no statistically significant difference of adverse events between topical tobramycin and placebo. No tobramycin resistant bacterial strains were reported from this study.

\section{Other emerging options}

Many adjunctive agents have been utilized to control CRS including antimycotics, ${ }^{95-98}$ anti-IgE, ${ }^{99}$ anti-IL5, ${ }^{100,101}$ antihistamine, ${ }^{102,103}$ aspirin desensitization, ${ }^{104}$ bacterial lysates, ${ }^{105-108}$ capsaicin, ${ }^{109}$ complementary and alternative medicine, ${ }^{3,110-114}$ decongestants, ${ }^{115}$ furosemide, ${ }^{116}$ immunosuppressants, ${ }^{117,118}$ leukotriene antagonists, ${ }^{119,120}$ nasal irrigation, ${ }^{121-127}$ mucolytic agents, ${ }^{128}$ phototherapy, ${ }^{129}$ probiotics, ${ }^{130}$ and proton pump inhibitors (PPIs). ${ }^{131}$ There was limited evidence on the effect of these options. We will focus this topic only on medications with positive effects.

\section{Anti-lgE}

Several investigators found that CRSwNP patients have higher IgE in polyps and serum than controls. ${ }^{132-134}$ One randomized controlled trial used omalizumab for 6 months compared with placebo in CRS patients. ${ }^{99}$ They found improvement of sinus opacification in CT-scans and the SNOT-20, but there was not a significant difference. 


\section{Anti-IL-5}

IL-5 is the key mediator in eosinophil activation. Sejima et al found that patients with CRSwNP had higher levels of IL-5 compared with patients with CRSsNP. ${ }^{138}$ There were some small Phase II randomized controlled trials that found a positive effect of reslizumab and mepolizumab in decreasing polyp size. ${ }^{100,101}$ These drugs may have a possible role in treatment of CRSwNP in the future.

\section{Bacterial lysates}

The mechanisms of bacterial lysates are hypothesized to enhance the process of postnatal maturation of Thelper (Th) 1 function and dendritic cells. ${ }^{105,106}$ The efficacy of bacterial lysates (Broncho-Vaxom, OM Pharma, Geneva, Switzerland) was investigated compared with placebo. ${ }^{107}$ They found a significant improvement in symptoms including headache, purulent discharge, cough, and expectoration in the bacterial lysates group. ${ }^{107}$

\section{Capsaicin}

The calcitonin gene-related peptide (CGRP) is a vasodilator agent present in sensory nerves and may play a major role in the vascular component of neurogenic inflammation. Repeated intranasal applications of capsaicin induced a reduction in both concentration of CGRP-like immunoreactivity and rhinitis symptoms. ${ }^{139}$ One randomized controlled trial found that patients treated with capsaicin showed a significant smaller staging of their nasal polyposis compared with the control group. ${ }^{109}$

\section{Complementary and alternative medicine}

The complementary and alternative medicines used to treat CRS include herbal medicine, vitamins, homeopathy, acupuncture, massage, reflexology, yoga, and chiropractics. ${ }^{110}$ Richstein and Mann ${ }^{111}$ compared the herbal preparation (European elder, common sorrel, cowslip, European vervain and gentian) with placebo, and found improvement of the overall clinical status and possible improvement on the radiological findings in the herbal preparation group (12/16 patients) and placebo group (6/15 patients). Another study reported a significant effect on nasal mucosa inflammation reduction and overall rating in the herbal preparation group, but no significant difference in other symptoms including nasal mucosa edema, nasal discharge, and breathing difficulties. ${ }^{12}$

\section{Furosemide}

Furosemide could induce cell shrinkage by mediating the net influx of osmotically active ions ${ }^{140}$ and hypothetically have immunomodulatory and anti-inflammatory effects in hyperactive airway disease. ${ }^{141,142}$ One randomized controlled trial compared topical furosemide versus oral methylprednisolone for 7 days preoperatively. ${ }^{116}$ Furosemide could significantly reduce the subjective and endoscopic score when compared to baseline but was not significant when compared to oral methylprednisolone. ${ }^{116}$

\section{Nasal irrigation}

Nasal irrigation has been introduced as an adjunctive treatment. It facilitates mechanical removal of mucus, infective pathogens, and inflammatory mediators and promotes ciliary beat frequency. Freeman et al ${ }^{121}$ studied the efficacy of saline irrigation post-endoscopic sinus surgery. At 3 weeks postoperatively, the outcomes showed a significant improvement of discharge in the saline douching group compared with no treatment $(P=0.046)$. However, at 3 months postoperatively, there was only a minimal difference with crusting $(P=0.18)$ and edema $(P=0.32)$, and no difference with adhesions, discharge, and polyps. ${ }^{121}$ Khianey et al also found a small clinical benefit of the nasal saline irrigation with minimal side effects. ${ }^{127}$

\section{Mucolytic agents}

Some studies used mucolytic agents as an adjunctive drug for treating patients with tenacious mucus. Majima et $\mathrm{al}^{128}$ assessed the efficacy of S-carboxymethylcysteine in CRS patients without nasal polyps or with small nasal polyps. After 12 weeks of treatment, the nasal discharge and post-nasal discharge were significantly improved in the S-carboxymethylcysteine group $(P=0.008$ and $P=0.002$, respectively). However, the SNOT-20 and CT scores were not significantly different between groups. ${ }^{128}$

\section{PPIs}

Esophageal reflux was considered a potential cause of CRS. Using PPIs to decrease acid reflux may reduce sinonasal mucosal damage. An uncontrolled trial evaluating PPIs in CRS patients reported improvement in sinus symptoms (nasal congestion, nasal drainage, sinus pressure, facial headache, malaise) and global satisfaction $(25 \%-89 \%$ and $91 \%$, respectively). ${ }^{131}$

\section{Phototherapy}

Near-infrared laser illumination (NILI), with or without photoactivated (PA) agents, has bactericidal and wound healing promoting effects which may have a potential role in managing 
CRS. Krespi et al ${ }^{129}$ conducted a prospective randomized study with 23 symptomatic post-surgical CRS patients comparing NILI versus NILI with PA. Both therapy arms demonstrated clinical efficacy. The SNOT-20 score change was 0.9 for the NILI group and 0.8 for the NILI with PA group $(P<0.05) .{ }^{129}$

\section{Surgery CRSsNP}

The aim of surgery includes clearing diseased mucosa, eliminating infection, relieving drainage obstruction, and restoring ventilation. Two randomized controlled trials compared the efficacy between surgery and medication in CRS. Hartog et al $^{140}$ showed no significant difference in overall cure rates between the medication group (sinus irrigation plus loracarbef) and surgical group (sinus irrigation plus loracarbef plus endoscopic sinus surgery). This result was similar to the result of Ragab et al, ${ }^{141}$ which showed no difference in total symptom scores in the medication group (erythromycin plus nasal steroid plus nasal douche) and surgical group (endoscopic sinus surgery plus nasal steroid plus nasal douche). The Cochrane review suggested that functional endoscopic sinus surgery has not been demonstrated to confer additional benefits to those obtained by medical treatment. ${ }^{142}$ We recommend surgical intervention only when there is no response to maximal medical treatment.

\section{CRSwNP}

Surgical intervention involves clearance of polyps and abnormal mucosa and opening of the sinus openings. There was limited evidence based on nonrandomized controlled trials which found that endoscopic sinus surgery was safe and effective. ${ }^{143}$

\section{Conclusion}

Several therapies have been proven by studies with a high level of evidence to improve clinical symptoms and objective outcomes. Some therapies still need validation through wellconducted studies, in which randomized controlled trials may be a difficult task due to confounding factors and trial participation. Even though it remains a challenge to cure the root cause of CRS, an algorithm of multidrug regimen and endoscopic sinus surgery after fully implemented medication can help to decrease the disease burden and improve the quality of life of this group of patients.

\section{Acknowledgment}

We would like to thank Associate Professor Kornkiat Snidvongs for his advice and English language editing.

\section{Disclosure}

The authors report no conflicts of interest in this work.

\section{References}

1. Fokkens W, Lund V, Mullol J; European Position Paper on Rhinosinusitis and Nasal Polyps group. European position paper on rhinosinusitis and nasal polyps 2007. Rhinol Suppl. 2007;(20):1-136.

2. Rosenfeld RM, Andes D, Bhattacharyya N, et al. Clinical practice guideline: adult sinusitis. Otolaryngol Head Neck Surg. 2007; 137(Suppl 3):S1-S31.

3. Fokkens WJ, Lund VJ, Mullol J, et al. EPOS 2012: European position paper on rhinosinusitis and nasal polyps 2012. A summary for otorhinolaryngologists. Rhinology. 2012;50(1):1-12.

4. Wang PC, Tai CJ, Lin MS, Chu CC, Liang SC. Quality of life in Taiwanese adults with chronic rhino-sinusitis. Qual Life Res. 2003; 12(4):443-448.

5. Gliklich RE, Metson R. The health impact of chronic sinusitis in patients seeking otolaryngologic care. Otolaryngol Head Neck Surg. 1995; 113(1):104-109.

6. Adams PF, Hendershot GE, Marano MA; Centers for Disease Control and Prevention/National Center for Health Statistics. Current estimates from the National Health Interview Survey, 1996. Vital Health Stat 10. 1999;200:1-203.

7. Collins JG. Prevalence of selected chronic conditions: United States, 1990-1992. Vital Health Stat 10. 1997;(194):1-89.

8. Shashy RG, Moore EJ, Weaver A. Prevalence of the chronic sinusitis diagnosis in Olmsted County, Minnesota. Arch Otolaryngol Head Neck Surg. 2004;130(3):320-323.

9. Bonfils P, Halimi P, Le Bihan C, Norès JM, Avan P, Landais P. Correlation between nasosinusal symptoms and topographic diagnosis in chronic rhinosinusitis. Ann Otol Rhinol Laryngol. 2005;114(1 Pt 1):74-83.

10. Hastan D, Fokkens WJ, Bachert C, et al. Chronic rhinosinusitis in Europe - an underestimated disease. A GA(2)LEN study. Allergy. 2011;66(9):1216-1223.

11. Ponikau JU, Sherris DA, Kern EB, et al. The diagnosis and incidence of allergic fungal sinusitis. Mayo Clin Proc. 1999;74(9):877-884.

12. Sasama J, Sherris DA, Shin SH, Kephart GM, Kern EB, Ponikau JU. New paradigm for the roles of fungi and eosinophils in chronic rhinosinusitis. Curr Opin Otolaryngol Head Neck Surg. 2005;13(1):2-8.

13. Van Crombruggen K, Zhang N, Gevaert P, Tomassen P, Bachert C. Pathogenesis of chronic rhinosinusitis: inflammation. J Allergy Clin Immunol. 2011;128(4):728-732.

14. Roca-Ferrer J, Garcia-Garcia FJ, Pereda J, et al. Reduced expression of COXs and production of prostaglandin $\mathrm{E}(2)$ in patients with nasal polyps with or without aspirin-intolerant asthma. JAllergy Clin Immunol. 2011; 128(1):66-72. e1.

15. Bachert C, Gevaert P, Holtappels G, Johansson SG, van Cauwenberge P. Total and specific IgE in nasal polyps is related to local eosinophilic inflammation. J Allergy Clin Immunol. 2001;107(4):607-614.

16. Bachert C, Zhang N, Patou J, van Zele T, Gevaert P. Role of staphylococcal superantigens in upper airway disease. Curr Opin Allergy Clin Immunol. 2008;8(1):34-38.

17. Kern RC, Conley DB, Walsh W, et al. Perspectives on the etiology of chronic rhinosinusitis: an immune barrier hypothesis. Am J Rhinol. 2008;22(6):549-559.

18. Foreman A, Holtappels G, Psaltis AJ, et al. Adaptive immune responses in Staphylococcus aureus biofilm-associated chronic rhinosinusitis. Allergy. 2011;66(11):1449-1456.

19. Xaubet A, Mullol J, López E, et al. Comparison of the role of nasal polyp and normal nasal mucosal epithelial cells on in vitro eosinophil survival. Mediation by GM-CSF and inhibition by dexamethasone. Clin Exp Allergy. 1994;24(4):307-317.

20. Mullol J, Xaubet A, López E, Roca-Ferrer J, Picado C. Comparative study of the effects of different glucocorticosteroids on eosinophil survival primed by cultured epithelial cell supernatants obtained from nasal mucosa and nasal polyps. Thorax. 1995;50(3):270-274. 
21. Mullol J, López E, Roca-Ferrer J, et al. Effects of topical antiinflammatory drugs on eosinophil survival primed by epithelial cells. Additive effect of glucocorticoids and nedocromil sodium. Clin Exp Allergy. 1997;27(12):1432-1441.

22. Xaubet A, Mullol J, Roca-Ferrer J, et al. Effect of budesonide and nedocromil sodium on IL-6 and IL-8 release from human nasal mucosa and polyp epithelial cells. Respir Med. 2001;95(5):408-414.

23. Mullol J, Roca-Ferrer J, Xaubet A, Raserra J, Picado C. Inhibition of GM-CSF secretion by topical corticosteroids and nedocromil sodium. A comparison study using nasal polyp epithelial cells. Respir Med. 2000;94(5):428-431

24. Mullol J, Xaubet A, Gaya A, et al. Cytokine gene expression and release from epithelial cells. A comparison study between healthy nasal mucosa and nasal polyps. Clin Exp Allergy. 1995;25(7):607-615.

25. Lal D, Hwang PH. Oral corticosteroid therapy in chronic rhinosinusitis without polyposis: a systematic review. Int Forum Allergy Rhinol. 2011;1(2):136-143.

26. Tosca MA, Cosentino C, Pallestrini E, et al. Medical treatment reverses cytokine pattern in allergic and nonallergic chronic rhinosinusitis in asthmatic children. Pediatr Allergy Immunol. 2003;14(3):238-241.

27. Subramanian HN, Schechtman KB, Hamilos DL. A retrospective analysis of treatment outcomes and time to relapse after intensive medical treatment for chronic sinusitis. Am J Rhinol. 2002;16(6):303-312.

28. Lal D, Scianna JM, Stankiewicz JA. Efficacy of targeted medical therapy in chronic rhinosinusitis, and predictors of failure. Am J Rhinol Allergy 2009;23(4):396-400.

29. Martinez-Devesa P, Patiar S. Oral steroids for nasal polyps. Cochrane Database Syst Rev. 2011;(7):CD005232.

30. Vaidyanathan S, Barnes M, Williamson P, Hopkinson P, Donnan PT, Lipworth B. Treatment of chronic rhinosinusitis with nasal polyposis with oral steroids followed by topical steroids: a randomized trial. Ann Intern Med. 2011;154(5):293-302.

31. Benitez P, Alobid I, de Haro J, et al. A short course of oral prednisone followed by intranasal budesonide is an effective treatment of severe nasal polyps. Laryngoscope. 2006;116(5):770-775.

32. Alobid I, Benitez P, Pujols L, et al. Severe nasal polyposis and its impact on quality of life. The effect of a short course of oral steroids followed by long-term intranasal steroid treatment. Rhinology. 2006;44(1):8-13.

33. Hissaria P, Smith W, Wormald PJ, et al. Short course of systemic corticosteroids in sinonasal polyposis: a double-blind, randomized, placebo-controlled trial with evaluation of outcome measures. JAllergy Clin Immunol. 2006;118(1):128-133.

34. Van Zele T, Gevaert P, Holtappels G, et al. Oral steroids and doxycycline: two different approaches to treat nasal polyps. J Allergy Clin Immunol. 2010;125(5):1069-1076. e4.

35. Rupa V, Jacob M, Mathews MS, Seshadri MS. A prospective, randomised, placebo-controlled trial of postoperative oral steroid in allergic fungal sinusitis. Eur Arch Otorhinolaryngol. 2010;267(2):233-238.

36. Snidvongs K, Kalish L, Sacks R, Craig JC, Harvey RJ. Topical steroid for chronic rhinosinusitis without polyps. Cochrane Database Syst Rev. 2011;(8):CD009274

37. Lund VJ, Black JH, Szabó LZ, Schrewelius C, Akerlund A. Efficacy and tolerability of budesonide aqueous nasal spray in chronic rhinosinusitis patients. Rhinology. 2004;42(2):57-62.

38. Qvarnberg Y, Kantola O, Salo J, Toivanen M, Valtonen H, Vuori E. Influence of topical steroid treatment on maxillary sinusitis. Rhinology. 1992;30(2):103-112.

39. Lavigne F, Cameron L, Renzi PM, et al. Intrasinus administration of topical budesonide to allergic patients with chronic rhinosinusitis following surgery. Laryngoscope. 2002;112(5):858-864.

40. Hansen FS, Djupesland PG, Fokkens WJ. Preliminary efficacy of fluticasone delivered by a novel device in recalcitrant chronic rhinosinusitis. Rhinology. 2010;48(3):292-299.

41. Dijkstra MD, Ebbens FA, Poublon RM, Fokkens WJ. Fluticasone propionate aqueous nasal spray does not influence the recurrence rate of chronic rhinosinusitis and nasal polyps 1 year after functional endoscopic sinus surgery. Clin Exp Allergy. 2004;34(9):1395-1400.
42. Jorissen M, Bachert C. Effect of corticosteroids on wound healing after endoscopic sinus surgery. Rhinology. 2009;47(3):280-286.

43. Aukema AA, Mulder PG, Fokkens WJ. Treatment of nasal polyposis and chronic rhinosinusitis with fluticasone propionate nasal drops reduces need for sinus surgery. J Allergy Clin Immunol. 2005;115(5):1017-1023

44. Bross-Soriano D, Arrieta-Gómez JR, Prado-Calleros H. Infections after endoscopic polypectomy using nasal steroids. Otolaryngol Head Neck Surg. 2004;130(3):319-322.

45. Ehnhage A, Olsson P, Kölbeck KG, et al; NAFS Study Group. Functional endoscopic sinus surgery improved asthma symptoms as well as PEFR and olfaction in patients with nasal polyposis. Allergy. 2009;64(5):762-769.

46. Holmberg K, Juliusson S, Balder B, Smith DL, Richards DH, Karlsson G. Fluticasone propionate aqueous nasal spray in the treatment of nasal polyposis. Ann Allergy Asthma Immunol. 1997;78(3):270-276.

47. Holmström M. Clinical performance of fluticasone propionate nasal drops. Allergy. 1999;54 Suppl 53:21-25.

48. Jankowski R, Klossek JM, Attali V, Coste A, Serrano E. Long-term study of fluticasone propionate aqueous nasal spray in acute and maintenance therapy of nasal polyposis. Allergy. 2009;64(6):944-950.

49. Jurkiewicz D, Zielnik-Jurkiewicz BAW. Effectiveness of fluticasone propionate in nasal polyps treatment. International Review of Allergology and Clinical Immunology. 2004;10(1):22-24.

50. Keith P, Nieminen J, Hollingworth K, Dolovich J. Efficacy and tolerability of fluticasone propionate nasal drops 400 microgram once daily compared with placebo for the treatment of bilateral polyposis in adults. Clin Exp Allergy. 2000;30(10):1460-1468.

51. Lund VJ, Flood J, Sykes AP, Richards DH. Effect of fluticasone in severe polyposis. Arch Otolaryngol Head Neck Surg. 1998;124(5):513-518.

52. Mastalerz L, Milewski M, Duplaga M, Nizankowska E, Szczeklik A. Intranasal fluticasone propionate for chronic eosinophilic rhinitis in patients with aspirin-induced asthma. Allergy. 1997;52(9):895-900.

53. Olsson P, Ehnhage A, Nordin S, Stjarne P; NAF2S2 Study Group. Quality of life is improved by endoscopic surgery and fluticasone in nasal polyposis with asthma. Rhinology. 2010;48(3):325-330.

54. Penttilä M, Poulsen P, Hollingworth K, Holmström M. Dose-related efficacy and tolerability of fluticasone propionate nasal drops 400 microg once daily and twice daily in the treatment of bilateral nasal polyposis: a placebo-controlled randomized study in adult patients. Clin Exp Allergy. 2000;30(1):94-102.

55. Rowe-Jones JM, Medcalf M, Durham SR, Richards DH, Mackay IS. Functional endoscopic sinus surgery: 5 year follow up and results of a prospective, randomised, stratified, double-blind, placebo controlled study of postoperative fluticasone propionate aqueous nasal spray. Rhinology. 2005;43(1):2-10.

56. Vlckova I, Navrátil P, Kana R, Pavlicek P, Chrbolka P, Djupesland PG. Effective treatment of mild-to-moderate nasal polyposis with fluticasone delivered by a novel device. Rhinology. 2009;47(4):419-426.

57. el Naggar M, Kale S, Aldren C, Martin F. Effect of Beconase nasal spray on olfactory function in post-nasal polypectomy patients: a prospective controlled trial. J Laryngol Otol. 1995;109(10):941-944.

58. Karlsson G, Rundcrantz H. A randomized trial of intranasal beclomethasone dipropionate after polypectomy. Rhinology. 1982;20(3):144-148.

59. Mygind N, Pedersen CB, Prytz S, Sørensen H. Treatment of nasal polyps with intranasal beclomethasone dipropionate aerosol. Clin Allergy. 1975;5(2):159-164.

60. Chalton R, Mackay I, Wilson R, Cole P. Double blind, placebo controlled trial of betamethasone nasal drops for nasal polyposis. Br Med J (Clin Res Ed). 1985;291(6498):788.

61. Passàli D, Bernstein JM, Passali FM, Damiani V, Passàli GC, Bellussi L. Treatment of recurrent chronic hyperplastic sinusitis with nasal polyposis. Arch Otolaryngol Head Neck Surg. 2003;129(6):656-659.

62. Small CB, Hernandez J, Reyes A, et al. Efficacy and safety of mometasone furoate nasal spray in nasal polyposis. J Allergy Clin Immunol. 2005;116(6):1275-1281. 
63. Stjärne P, Mosges R, Jorissen M, et al. A randomized controlled trial of mometasone furoate nasal spray for the treatment of nasal polyposis. Arch Otolaryngol Head Neck Surg. 2006;132(2):179-185.

64. Stjärne P, Blomgren K, Cayé-Thomasen P, Salo S, Søderstrøm T. The efficacy and safety of once-daily mometasone furoate nasal spray in nasal polyposis: a randomized, double-blind, placebo-controlled study. Acta Otolaryngol. 2006;126(6):606-612.

65. Dingsør G, Kramer J, Olsholt R, Søderstrøm T. Flunisolide nasal spray $0.025 \%$ in the prophylactic treatment of nasal polyposis after polypectomy. A randomized, double blind, parallel, placebo controlled study. Rhinology. 1985;23(1):49-58.

66. Drettner B, Ebbesen A, Nilsson M. Prophylactive treatment with flunisolide after polypectomy. Rhinology. 1982;20(3):149-158.

67. Filiaci F, Passali D, Puxeddu R, Schrewelius C. A randomized controlled trial showing efficacy of once daily intranasal budesonide in nasal polyposis. Rhinology. 2000;38(4):185-190.

68. Hartwig S, Lindén M, Laurent C, Vargö AK, Lindqvist N. Budesonide nasal spray as prophylactic treatment after polypectomy (a double blind clinical trial). J Laryngol Otol. 1988;102(2):148-151.

69. Holopainen E, Grahne B, Malmberg H, Mäkinien J, Lindqvist N. Budesonide in the treatment of nasal polyposis. Eur J Respir Dis Suppl. 1982;122:221-228.

70. Jankowski R, Schrewelius C, Bonfils P, et al. Efficacy and tolerability of budesonide aqueous nasal spray treatment in patients with nasal polyps. Arch Otolaryngol Head Neck Surg. 2001;127(4):447-452.

71. Vendelo Johansen L, Illum P, Kristensen S, Winther L, Vang Petersen S, Synnerstad B. The effect of budesonide (Rhinocort) in the treatment of small and medium-sized nasal polyps. Clin Otolaryngol Allied Sci. 1993;18(6):524-527.

72. Johansson L, Holmberg K, Melen I, Stierna P, Bende M. Sensitivity of a new grading system for studying nasal polyps with the potential to detect early changes in polyp size after treatment with a topical corticosteroid (budesonide). Acta Otolaryngol. 2002;122(1):49-53.

73. Lildholdt T, Rundcrantz H, Lindqvist N. Efficacy of topical corticosteroid powder for nasal polyps: a double-blind, placebo-controlled study of budesonide. Clin Otolaryngol Allied Sci. 1995;20(1):26-30.

74. Ruhno J, Andersson B, Denburg J, et al. A double-blind comparison of intranasal budesonide with placebo for nasal polyposis. J Allergy Clin Immunol. 1990;86(6 Pt 1):946-953.

75. Tos M, Svendstrup F, Arndal H, et al. Efficacy of an aqueous and a powder formulation of nasal budesonide compared in patients with nasal polyps. Am J Rhinol. 1998;12(3):183-189.

76. Giger R, Pasche P, Cheseaux C, et al. Comparison of once- versus twice-daily use of beclomethasone dipropionate aqueous nasal spray in the treatment of allergic and non-allergic chronic rhinosinusitis. Eur Arch Otorhinolaryngol. 2003;260(3):135-140.

77. Pandak N, Pajić-Penavić I, Sekelj A, Tomić-Paradžik M, Cabraja I, Miklaušić B. Bacterial colonization or infection in chronic sinusitis. Wien Klin Wochenschr. 2011;123(23-24):710-713.

78. Piromchai P, Thanaviratananich S, Laopaiboon M. Systemic antibiotics for chronic rhinosinusitis without nasal polyps in adults. Cochrane Database Syst Rev. 2011;(5):CD008233.

79. Legent F, Bordure P, Beauvillain C, Berche P. A double-blind comparison of ciprofloxacin and amoxycillin/clavulanic acid in the treatment of chronic sinusitis. Chemotherapy. 1994;40 Suppl 1:8-15.

80. Namyslowski G, Misiolek M, Czecior E, et al. Comparison of the efficacy and tolerability of amoxycillin/clavulanic acid $875 \mathrm{mg}$ b.i.d. with cefuroxime $500 \mathrm{mg}$ b.i.d. in the treatment of chronic and acute exacerbation of chronic sinusitis in adults. J Chemother. 2002;14(5): 508-517.

81. Suzuki H, Shimomura A, Ikeda K, Oshima T, Takasaka T. Effects of long-term low-dose macrolide administration on neutrophil recruitment and IL-8 in the nasal discharge of chronic sinusitis patients. Tohoku J Exp Med. 1997;182(2):115-124.

82. Scadding GK, Lund VJ, Darby YC. The effect of long-term antibiotic therapy upon ciliary beat frequency in chronic rhinosinusitis. J Laryngol Otol. 1995;109(1):24-26.
83. Ichimura K, Shimazaki Y, Ishibashi T, Higo R. Effect of new macrolide roxithromycin upon nasal polyps associated with chronic sinusitis. Auris, nasus, larynx. 1996;23:48-56.

84. Nishi K, Mizuguchi M, Tachibana H, et al. [Effect of clarithromycin on symptoms and mucociliary transport in patients with sino-bronchial syndrome.] Nihon Kyōbu Shikkan Gakkai Zasshi. 1995;33(12): 1392-1400. Japanese.

85. Rubin BK, Druce H, Ramirez OE, Palmer R. Effect of clarithromycin on nasal mucus properties in healthy subjects and in patients with purulent rhinitis. Am J Respir Crit Care Med. 1997;155(6):2018-2023.

86. Wallwork B, Coman W, Mackay-Sim A, Greiff L, Cervin A. A doubleblind, randomized, placebo-controlled trial of macrolide in the treatment of chronic rhinosinusitis. Laryngoscope. 2006;116(2): 189-193.

87. Videler WJ, Badia L, Harvey RJ, et al. Lack of efficacy of longterm, low-dose azithromycin in chronic rhinosinusitis: a randomized controlled trial. Allergy. 2011;66(11):1457-1468.

88. Schalek P, Petrás P, Klement V, Hahn A. Short-term antibiotics treatment in patients with nasal polyps and enterotoxins producing Staphylococcus aureus strains. Eur Arch Otorhinolaryngol. 2009; 266(12):1909-1913.

89. Yamada T, Fujieda S, Mori S, Yamamoto H, Saito H. Macrolide treatment decreased the size of nasal polyps and IL-8 levels in nasal lavage. Am J Rhinol. 2000;14(3):143-148.

90. Maruyama S, Yoshioka H, Fujita K, Takimoto M, Satake Y. Sensitivity of group A streptococci to antibiotics. Prevalence of resistance to erythromycin in Japan. Am J Dis Child. 1979;133(11):1143-1145.

91. Seppälä H, Klaukka T, Vuopio-Varkila J, et al. The effect of changes in the consumption of macrolide antibiotics on erythromycin resistance in group A streptococci in Finland. Finnish Study Group for Antimicrobial Resistance. N Engl J Med. 1997;337(7):441-446.

92. Desrosiers MY, Salas-Prato M. Treatment of chronic rhinosinusitis refractory to other treatments with topical antibiotic therapy delivered by means of a large-particle nebulizer: results of a controlled trial. Otolaryngol Head Neck Surg. 2001;125(3):265-269.

93. Videler WJ, van Drunen CM, Reitsma JB, Fokkens WJ. Nebulized bacitracin/colimycin: a treatment option in recalcitrant chronic rhinosinusitis with Staphylococcus aureus? A double-blind, randomized, placebo-controlled, cross-over pilot study. Rhinology. 2008;46(2):92-98.

94. Lim M, Citardi MJ, Leong JL. Topical antimicrobials in the management of chronic rhinosinusitis: a systematic review. Am J Rhinol. 2008;22(4):381-389.

95. Ponikau JU, Sherris DA, Kern EB, et al. The diagnosis and incidence of allergic fungal sinusitis. Mayo Clinic proceedings. Mayo Clin Proc. 1999;74(9):877-884.

96. Liang KL, Su MC, Shiao JY, et al. Amphotericin B irrigation for the treatment of chronic rhinosinusitis without nasal polyps: a randomized, placebo-controlled, double-blind study. Am J Rhinol. 2008;22(1):52-58.

97. Ponikau JU, Sherris DA, Kita H, Kern EB. Intranasal antifungal treatment in 51 patients with chronic rhinosinusitis. JAllergy Clin Immunol. 2002;110(6):862-866

98. Kennedy DW, Kuhn FA, Hamilos DL, et al. Treatment of chronic rhinosinusitis with high-dose oral terbinafine: a double blind, placebocontrolled study. Laryngoscope. 2005;115(10):1793-1799.

99. Pinto JM, Mehta N, DiTineo M, Wang J, Baroody FM, Naclerio RM. A randomized, double-blind, placebo-controlled trial of anti-IgE for chronic rhinosinusitis. Rhinology. 2010;48(3):318-324.

100. Gevaert P, Lang-Loidolt D, Lackner A, et al. Nasal IL-5 levels determine the response to anti-IL-5 treatment in patients with nasal polyps. J Allergy Clin Immunol. 2006;118(5):1133-1141.

101. Gevaert P, Van Bruaene N, Cattaert T, et al. Mepolizumab, a humanized anti-IL-5 mAb, as a treatment option for severe nasal polyposis. $J$ Allergy Clin Immunol. 2011;128(5):989-995. e1-e8.

102. Haye R, Aanesen JP, Burtin B, Donnelly F, Duby C. The effect of cetirizine on symptoms and signs of nasal polyposis. J Laryngol Otol. 1998;112(11):1042-1046. 
103. Braun JJ, Alabert JP, Michel FB, et al. Adjunct effect of loratadine in the treatment of acute sinusitis in patients with allergic rhinitis. Allergy. 1997;52(6):650-655.

104. ParikhAA, Scadding GK. Intranasal lysine-aspirin in aspirin-sensitive nasal polyposis: a controlled trial. Laryngoscope. 2005;115(8): 1385-1390.

105. Bowman LM, Holt PG. Selective enhancement of systemic Th1 immunity in immunologically immature rats with an orally administered bacterial extract. Infect Immun. 2001;69(6):3719-3727.

106. Spisek R, Brazova J, Rozkova D, Zapletalova K, Sediva A, Bartunkova J. Maturation of dendritic cells by bacterial immunomodulators. Vaccine. 2004;22(21-22):2761-2768.

107. Heintz B, Schlenter WW, Kirsten R, Nelson K. Clinical efficacy of Broncho-Vaxom in adult patients with chronic purulent sinusitis a multi-centric, placebo-controlled, double-blind study. Int J Clin Pharmacol Ther Toxicol. 1989;27(11):530-534.

108. Schaad UB, Mütterlein R, Goffin H; BV-Child Study Group. Immunostimulation with OM-85 in children with recurrent infections of the upper respiratory tract: a double-blind, placebo-controlled multicenter study. Chest. 2002;122(6):2042-2049.

109. Zheng C, Wang Z, Lacroix JS. Effect of intranasal treatment with capsaicin on the recurrence of polyps after polypectomy and ethmoidectomy. Acta Otolaryngol. 2000;120(1):62-66.

110. Yakirevitch A, Bedrin L, Migirov L, Wolf M, Talmi YP. Use of alternative medicine in Israeli chronic rhinosinusitis patients. J Otolaryngol Head Neck Surg. 2009;38(4):517-520.

111. Richstein A, Mann W. Zur Behandlung der chronischen Sinusitis mit Sinupret [Treatment of chronic sinusitis with Sinupret.] Ther Ggw. 1980;119(9):1055-1060. German.

112. Taub SJ. The use of bromelains in sinusitis: a double-blind clinical evaluation. Eye Ear Nose Throat Mon. 1967;46(3):361-362.

113. Guo R, Cantery PH, Ernst E. Herbal Medicines for the Treatment of Rhinosinusitis: A Systematic Review. Otolaryngol Head Neck Surg. 2006;135(4):496-506.

114. Zimmer M. Gezielte konservative Therapie der akuten Sinusitis in der HNO-Praxis [Therapy of acute sinusitis]. Therapiewoche. 1985;35:4024-4028. German.

115. Johansson L, Oberg D, Melén I, Bende M. Do topical nasal decongestants affect polyps? Acta Otolaryngol. 2006;126(3):288-290.

116. Kroflic B, Coer A, Baudoin T, Kalogjera L. Topical furosemide versus oral steroid in preoperative management of nasal polyposis. Eur Arch Otorhinolaryngol. 2006;263(8):767-771.

117. Asplund MS, Hagberg H, Holmström M. Chemotherapy in severe nasal polyposis - a possible beneficial effect? A report of three cases. Rhinology. 2010;48(3):374-376.

118. Buyukozturk S, Gelincik A, Aslan I, Aydin S, Colakoglu B, Dal M. Methotrexate: can it be a choice for nasal polyposis in aspirin exacerbated respiratory disease? J Asthma. 2009;46(10):1037-1041.

119. Stewart RA, Ram B, Hamilton G, Weiner J, Kane KJ. Montelukast as an adjunct to oral and inhaled steroid therapy in chronic nasal polyposis. Otolaryngol Head Neck Surg. 2008;139(5):682-687.

120. Pauli C, Fintelmann R, Klemens C, et al. Polyposis nasi--Besserung der Lebensqualitat durch Leukotrien-Rezeptorantagonisten [Polyposis nasi - improvement in quality of life by the influence of leukotrien receptor antagonists]. Laryngorhinootologie. 2007;86(4):282-286. German.

121. Freeman SR, Sivayoham ES, Jepson K, de Carpentier J. A preliminary randomised controlled trial evaluating the efficacy of saline douching following endoscopic sinus surgery. Clin Otolaryngol. 2008;33(5): $462-465$.

122. Pynnonen MA, Mukerji SS, Kim HM, Adams ME, Terrell JE. Nasal saline for chronic sinonasal symptoms: a randomized controlled trial. Arch Otolaryngol Head Neck Surg. 2007;133(11):1115-1120.

123. Raza T, Elsherif HS, Zulianello L, Plouin-Gaudon I, Landis BN, Lacroix JS.Nasal lavage with sodium hypochlorite solution in Staphylococcus aureus persistent rhinosinusitis. Rhinology. 2008;46(1):15-22.
124. Weissman JD, Fernandez F, Hwang PH. Xylitol nasal irrigation in the management of chronic rhinosinusitis: A pilot study. The Laryngoscope. 2011;121(11):2468-2472.

125. Chiu AG, Palmer JN, Woodworth BA, et al. Baby shampoo nasal irrigations for the symptomatic post-functional endoscopic sinus surgery patient. Am J Rhinol. 2008;22(1):34-37.

126. Harvey R, Hannan SA, Badia L, Scadding G. Nasal saline irrigations for the symptoms of chronic rhinosinusitis. Cochrane Database Syst Rev. 2007;(3):CD006394.

127. Khianey R, Oppenheimer J. Is nasal saline irrigation all it is cracked up to be? Ann Allergy Asthma Immunol. 2012;109(1):20-28.

128. Majima Y, Kurono Y, Hirakawa K, et al. Efficacy of combined treatment with S-carboxymethylcysteine (carbocisteine) and clarithromycin in chronic rhinosinusitis patients without nasal polyp or with small nasal polyp. Auris Nasus Larynx. 2012;39(1):38-47.

129. Krespi YP, Kizhner V. Phototherapy for chronic rhinosinusitis. Lasers Surg Med. 2011;43(3):187-191.

130. Mukerji SS, Pynnonen MA, Kim HM, Singer A, Tabor M, Terrell JE. Probiotics as adjunctive treatment for chronic rhinosinusitis: a randomized controlled trial. Otolaryngol Head Neck Surg. 2009; 140(2):202-208.

131. DiBaise JK, Olusola BF, Huerter JV, Quigley EM. Role of GERD in chronic resistant sinusitis: a prospective, open label, pilot trial. Am J Gastroenterol. 2002;97(4):843-850.

132. Ikeda K, Shiozawa A, Ono N, et al. Subclassification of chronic rhinosinusitis with nasal polyp based on eosinophil and neutrophil. Laryngoscope. 2013. [Epub ahead of print].

133. Xu M, Zhao F, Shen A, Zhou H. [Serum allergen-specific IgE in patients with eosinophilic nasal polyps]. Lin Chung Er Bi Yan Hou Tou Jing Wai Ke Za Zhi 2012;26(17):772-3. Chinese.

134. Sejima T, Holtappels G, Kikuchi H, et al. Cytokine profiles in Japanese patients with chronic rhinosinusitis. Allergol Int. 2012;61(1):11522.

135. Sejima T, Holtappels G, Kikuchi H, Imayoshi S, Ichimura K, Bachert C. Cytokine profiles in Japanese patients with chronic rhinosinusitis. Allergol Int. 2012;61(1):115-122.

136. Lacroix JS, Buvelot JM, Polla BS, Lundberg JM. Improvement of symptoms of non-allergic chronic rhinitis by local treatment with capsaicin. Clin Exp Allergy. 1991;21(5):595-600.

137. Iwamoto LM, Fujiwara N, Nakamura KT, Wada RK. Na-K-2Cl cotransporter inhibition impairs human lung cellular proliferation. Am J Physiol Lung Cell Mol Physiol. 2004;287(3):L510-L514.

138. Yuengsrigul A, Chin TW, Nussbaum E. Immunosuppressive and cytotoxic effects of furosemide on human peripheral blood mononuclear cells. Ann Allergy Asthma Immunol. 1999;83(6 Pt 1):559-566.

139. Prandota J. Furosemide: progress in understanding its diuretic, antiinflammatory, and bronchodilating mechanism of action, and use in the treatment of respiratory tract diseases. Am J Ther. 2002;9(4): 317-328.

140. Hartog B, van Benthem PP, Prins LC, Hordijk GJ. Efficacy of sinus irrigation versus sinus irrigation followed by functional endoscopic sinus surgery. Ann Otol Rhinol Laryngol. 1997;106(9):759-766.

141. Ragab SM, Lund VJ, Scadding G. Evaluation of the medical and surgical treatment of chronic rhinosinusitis: a prospective, randomised, controlled trial. Laryngoscope. 2004;114(5):923-930.

142. Khalil HS, Nunez DA. Functional endoscopic sinus surgery for chronic rhinosinusitis. Cochrane Database Syst Rev. 2006;(3):CD004458.

143. Dalziel K, Stein K, Round A, Garside R, Royle P. Systematic review of endoscopic sinus surgery for nasal polyps. Health Technol Assess. 2003;7(17):iii, 1-159. 


\section{Publish your work in this journal}

The International Journal of General Medicine is an international, A key focus is the elucidation of disease processes and management peer-reviewed open-access journal that focuses on general and internal medicine, pathogenesis, epidemiology, diagnosis, monitoring and treatment protocols. The journal is characterized by the rapid reporting of reviews, original research and clinical studies across all disease areas. protocols resulting in improved outcomes for the patient.The manuscript management system is completely online and includes a very quick and fair peer-review system. Visit http://www.dovepress.com/ testimonials.php to read real quotes from published authors.

Submit your manuscript here: http://www.dovepress.com/international-journal-of-general-medicine-journal 